Etnográfica

Revista do Centro em Rede de Investigação em

Antropologia

vol. $26(1) \mid 2022$

Vol. $26(1)$

\title{
La venta ambulante en Buenos Aires: economía(s) (i)legales, estética y circulación de objetos
}

A venda ambulante em Buenos Aires: economia(s) (i)legais, estética e circulação de objetos

\section{Mariano Daniel Perelman}

\section{(2) OpenEdition}

Journals

Edición electrónica

URL: https://journals.openedition.org/etnografica/11275

DOI: $10.4000 /$ etnografica. 11275

ISSN: 2182-2891

\section{Editor}

Centro em Rede de Investigação em Antropologia

Edición impresa

Paginación: 109-123

ISSN: 0873-6561

Referencia electrónica

Mariano Daniel Perelman, «La venta ambulante en Buenos Aires: economía(s) (i)legales, estética y circulación de objetos», Etnográfica [En línea], vol. 26 (1) | 2022, Publicado el 25 febrero 2022 consultado el 30 junio 2022. URL: http://journals.openedition.org/etnografica/11275 ; DOI: https:// doi.org/10.4000/etnografica. 11275

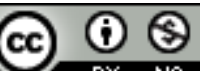

Etnográfica is licensed under a Creative Commons Attribution-NonCommercial 4.0 International License. 


\section{La venta ambulante en Buenos Aires: economía(s) (i)legales, estética y circulación de objetos}

\section{Mariano Daniel Perelman}

En Buenos Aires los transportes públicos son lugares de venta. Tanto las prácticas de los vendedores como los productos que se ofrecen suelen ser cuestionados por estar por fuera de ley. A partir de seguir cosas y personas el texto muestra la dificultad de generar fronteras entre "distintas economías" así como reflexiona sobre el modo en que las investigaciones sociales contribuyen a generar demarcaciones externas a las configuraciones que analizan. En este texto me interesa mostrar el entramado de relaciones que producen el comercio ambulante en trenes y colectivos de Buenos Aires. Para ello voy a centrarme en dos líneas: las cosas y su estetización. El análisis de estas dos dimensiones permite mostrar la construcción de ese fetichismo en tanto la legalidad de los productos no emana de las cosas en si sino del contexto (y la forma) en que circulan.

PALABRAS CLAVE: ilegalismos, venta ambulante, Buenos Aires, circuito de comercio, estética.

A venda ambulante em Buenos Aires: economia(s) (i)legais, estética e circulação de objetos - Em Buenos Aires, os transportes públicos são lugares de venda. Tanto as práticas dos vendedores quanto os produtos oferecidos são frequentemente postos em causa por estarem fora da lei. Partindo de seguir coisas e pessoas, o texto mostra a dificuldade em gerar fronteiras entre "economias diferentes", bem como de refletir sobre a forma como a pesquisa social contribui para gerar demarcações externas às configurações que analisa. Neste texto, estou interessado em mostrar a rede de relações produzida pelo comércio ambulante em comboios e autocarros em Buenos Aires. Para isso, vou concentrar-me em duas linhas: as coisas e a sua estetização. A análise dessas duas dimensões permite mostrar a construção desse fetichismo, na medida em que a legalidade dos produtos não emana das próprias coisas, mas do contexto (e do modo) em que circulam.

PALAVRAS-CHAVE: ilegalismos, venda ambulante, Buenos Aires, circuito comercial, estética.

PERELMAN, Mariano (mdperelman@conicet.gov.ar) - Investigador independiente del Consejo Nacional de Investigaciones Científicas y Técnicas (Conicet) y docente del Departamento de Antropología de la Universidad de Buenos Aires (UBA), Argentina. 


\section{INTRODUCCIÓN}

Son las 4:32 de la tarde, el tren comienza lentamente su salida de la terminal de Constitución. Juan empieza a caminar por el vagón en el que sólo unas cuantas personas van paradas. Pasa con su heladerita de telgopor llena de gaseosas. Tras él, comienza su caminata Esteban con un puñado de medias de la mano y otras tantas en un bolso que apoya e el piso para ofrecer a los pasajeros. Luego de Esteban, aparece Pedro que vende películas "truchas", piratas, copiadas. Se suceden las estaciones y los vendedores. Medias, cuadernos, auriculares, golosinas, bebidas, libros, curitas, cuchillos, cinturones, pilas, helados son algunos de los productos que se pueden adquirir en el viaje. Varios otros piden dinero, y músicos tocan instrumentos a cambio de monedas.

En Buenos Aires los transportes públicos son lugares de venta para miles de personas. Los recorridos de los vendedores no se restringen a los ómnibus y trenes. Son una constelación de relaciones tempo-espaciales propia y, a su vez, compartida. Estos territorios pueden incluir negocios mayoristas para comprar los productos, lugares de socialización donde se entablan relaciones personales, se fijan precios, se pasan datos sobre la mercadería, así como los espacios de venta. Tanto las personas como las cosas dentro de la constelación se transforman.

En este texto me interesa mostrar el entramado de relaciones que producen el comercio ambulante en trenes y colectivos de Buenos Aires. Para ello voy a centrarme en dos líneas: las cosas y su estetización.

La venta callejera es una práctica de intercambio de bienes donde circulan objetos, dinero, prestigio, deudas, sentidos. Analizarla cómo una economía (popular) e ilegal no permite ver la pluralidad de procesos que allí ocurren. Me interesa mostrar las diferentes formas en que se presentan; las cosas (y las personas) no remiten solo a una relación con la ley sino al mundo de la venta ambulante. Refiero al mundo de la venta ambulante en tanto que es posible identificar un campo de relaciones y vínculos más o menos estrechos, que van conformando una cierta "dimensión experiencial" y moral (Pita 2005). En estos mundos se articulan distintos circuitos de venta y están construidos a partir de diferentes maneras pensar la vida. Estas vidas y circuitos están conectados por "cosas", "personas", "discursos". Seguir a las personas permite mostrar la construcción de ese fetichismo en tanto la legalidad de los productos no emana de las cosas en si sino del contexto (y la forma) en que circulan. Esto no quiere decir que hay que desechar las nociones de informal e ilegal. Antes bien, me interesa pensarlas como categorías nativas (del Estado, de académicos y de los propios actores involucrados en la venta) que pueden ser movilizadas con mayor o menor éxito. Tendiendo presente este marco, mi trabajo se vale de las perspectivas que buscan alejarse de las miradas normativas sobre las prácticas económicas legales/ilegales (Misse 2008; Perelman 2018; Renoldi 2015; 
Sandoval Hernández 2017) para comprenderlas en la configuración social en la que las prácticas se disputan.

Como las prácticas son plurales antes que buscar el origen único o las causas y motivos (Thévenot 2016) por el que se producen formas específicas de vender, me parece más importante centrarme en las cadenas de acciones y transformaciones que se producen así como en "las diferentes formas de calificación de personas en el trabajo [...], que se apoyan en una pluralidad de formas de legitimación y de justificación" (Thévenot 2015: 47). La pugna por inscribir una actividad en la gramática de lo legal/ilegal debe ser entendida como una disputa de sentidos que - claro está - tiene efectos en los modos de acceso a la vida (Fernández Álvarez et al. 2019; Perelman 2018).

El texto que se basa en el trabajo de campo realizado entre 2011 y 2016 en diferentes líneas de trenes y ómnibus de Buenos Aires está organizado en dos grandes ejes. En primer lugar abordaré la circulación de las cosas, personas y discursos para luego centrarme en la importancia de la construcción estética de los productos.

\section{EL CIRCUITO AMBULANTE}

Lo que se engloba bajo la etiqueta de consumo popular es en realidad una multiplicidad de prácticas, relaciones, acciones. A veces es delimitado por el espacio en que las mercaderías circulan, otras veces por el producto mismo, también por quiénes intercambian o consumen. En su estudio sobre la sulanca, para pensar las prácticas económicas que no se encuadran dentro de lo establecido por los marcos legales, Rabossi (2008: 165) ha marcado la necesidad de reflexionar sobre qué hay en ellas: "Si hay objetos que son formalmente iguales aquello que las distingue es algo "que se aferra a los productos del trabajo' " - utilizando la expresión de Marx - y que las constituye tal como se nos presentan en su forma contemporánea. Y ese algo son las propiedades legales atribuidas a las cosas basadas en una historia de las formas en que producción y comercialización fueron reglamentadas y padronizadas en los distintos espacios jurisdiccionales que operan en un determinado lugar.

Seguir las cosas permite mostrar una articulación compleja entre diferentes circuitos (Zelizer 2004) y esferas. La existencia de circuitos puede ser pensada de manera entrelazada. Sólo existe un circuito porque tiene una frontera que lo delimitaría con otro. El comercio popular y - dentro de éste el circuito de comercio de la venta ambulante - se genera con y contra otros circuitos que no son escindibles. Guimarães, estudiando el cuidado - inspirándose en la noción de circuito de Zelizer - planteó la necesidad de pensar en una pluralidad de configuraciones sobre las cuales se organiza el trabajo de cuidado. Estos circuitos son resultado de un intenso trabajo que se produce en las configuraciones mismas (Guimarães 2019). Tensionando un poco más la posición de 
Guimarães es posible pensar en diferentes regímenes de valor no solo en distintos circuitos sino también en un mismo circuito. Pensarlos como homogéneos no permite ver la pluralidad de procesos, los usos situacionales y el modo en que los actores traen argumentos y los ponen en funcionamiento.

\section{El camino de las cosas}

Edgardo había llegado al local donde compra su mercadería a las 16 horas. Su turno de trabajo en comenzaba a las 18 horas, momento en el que se para en el andén y comienza a ofrecer las bebidas. Luego, cuando la hora pico termina, se sube a los trenes para ofrecer gaseosas y cervezas. En el local compró dos packs de latas de Coca Cola, uno de Sprite, dos de cerveza. "Algo me sobró de ayer" me dice mientras mete la mercadería en la heladerita de telgopor llena de hielo. "Tienen que estar bien frías. Mínimo dos horas de heladera" dice mientras cierra la tapa. "La bebida se vende sola. Vos tenés que pasar diciendo 'gaseosa, cerveza fría' y listo”. Así lo hace, pasa entre los cansados cuerpos de los trabajadores que vuelven a sus hogares en el conurbano bonaerense.

Carlos camina las cuadras que separan la estación del local en el que se provee de golosinas, galletitas y alfajores. Compra varias cajas de chocolates marca Cofler. "Están a buen precio" me dice, "además la gente ya me conoce, y con este día los chocolates salen como piña". Llega a la estación donde saluda al inspector y pasa los molinetes. Se apoya en una baranda justo cuando Pedro, otro vendedor lo llama con gesto. Se acerca a charlar. El tren llega, Caros se sube a un vagón y Pedro - un "busca de bolso" - se sube dos vagones atrás. Ambos comenzarán el ritual de venta. Carlos durante su speach hace hincapié en la calidad del producto, en su fecha de vencimiento. "Lleva precio, lleva calidad. Chocolate de primera marca, con su fecha de vencimiento para que la persona que quiera pueda consultar" dice mientras camina entre los asientos con dos barras en una mano que forman una $\mathrm{V}$ y la caja en la otra.

José vende medias desde hace más de 15 años en una de las líneas de trenes de la Ciudad de Buenos Aires. Se despierta todas las mañanas alrededor de las ocho. Desayuna y sale al taller que las hace. "Son buenísimas. Hacen 'Adidas'”, dice mientras saca un par y me las muestra. Luego sube a su auto que deja estacionado cerca de la estación y se toma un café con un grupo de vendedores. A muchos de ellos los ve también en la iglesia a la que asisten juntos. Luego el grupo camina hasta la estación y de a poco se van subiendo a distintos vagones y trenes. José lleva un pequeño bolso cruzado. El bolso está abierto y de él se asoman algunos pares de medias revueltos. En la mano lleva tres. Pasa por el pasillo ofreciendo "en promoción" tres pares de media por 150 pesos.

Tanto José, Carlos y Edgardo venden cosas que pasan por diferentes estatus. Seguir un producto permite mostrar las transacciones entre circuitos con fronteras porosas (Telles 2009; Kessler 2013). Al mismo tiempo habilita ver que no son las cosas ni las transacciones en si las que (i)legalizan a los productos. 
Los vendedores de golosinas con los que hice trabajo de campo suelen comprar a negocios sus productos al por mayor. Las gaseosas de Edgardo hacen este camino. Los mayoristas compran a su vez a otros mayoristas o directamente a fábricas. Los mayoristas venden a los vendedores - ya sin factura, o sea en negro - a los vendedores que a su vez ofrecen estos productos.

Las medias de José son un producto "trucho" que es producido por hombres y mujeres "en negro". José las compra también "en negro" y luego las vende sin pagar impuestos por ello. El hilo y la tela que sirven para la confección de indumentaria son producidos de forma legal. Las gaseosas de Edgardo y los chocolates de Carlos son, en cambio, producidas por dos de las empresas alimenticias más grandes de Argentina. Más allá de la evasión fiscal que pueden hacer las grandes empresas, esos productos parecen venir del mercado "formal" que pasan a tener un carácter ilegal al ser vendidos en la venta ambulante.

Mucho de los productos pasan casi toda su vida por la "economía informal". Un caso paradigmático es el de los CD y DVD "truchos". ${ }^{1}$ Como las películas que ofrece Esteban. Algunos vendedores arman los CD en sus casas. Otros, en cambio, son comprados para ser vendidos. Cuando conocí a Esteban rápidamente comprendí el lugar que ocupaba en el mundo de la venta ambulante de una línea de ferrocarril. La primera vez que oí hablar de él fue en un bar en una charla con Juan Carlos, un vendedor de revistas que tiene un puesto en una concurrida estación. Mientras conversábamos, Esteban pasó por la puerta del bar. Al verlo, Juan Carlos me dijo: “ite gustan las películas?, tenés que hablar con él”, señalando la figura de un hombre de unos 50 años que más tarde sabría que se llama Esteban. "Sabe todo. Es mi crítico que cine. Vos contale qué películas te gustan que él te va a recomendar. No falla nunca”.

Los vendedores son eslabones centrales de la provisión de bienes y servicios. Así como los vendedores tienen rutinas fijas con horario, muchos pasajeros también las tienen. A partir de este lugar de ser conocidos, los vendedores generaban una serie de relaciones de afinidad que contribuía al establecimiento del mercado de venta ambulante: se producía predictibilidad en términos de ingresos para los vendedores, se generaban deudas morales que contribuían a la circulación de cierto tipo de mercadería de calidad (Perelman 2013). Así, un vendedor de gaseosas hablaba sobre cómo sus clientes lo esperaban para tomar algo al final de día en su vuelta a casa. Un vendedor de CD me contaba que creaba sus productos pensando en que todos los temas tenían que ser buenos. "iTe acordás de esos compacts de grandes éxitos que vos comprabas y en

l Lo "trucho", lo ilegal no está por fuera de lo legal, sino que es un efecto de ello (Tiscornia 2007). Existe un campo que ha analizado este tipo de producto mostrando que no es una simple réplica, sino que adquiere sentidos específicos en el circuito en que circulan (Lins Ribeiro 2018; Alba Vega, Lins Ribeiro y Mathews 2015; Pinheiro-Machado 2018; Aguiar 2013). Estos productos no solo pueden ser pensados como parte de un sistema "desde abajo" o no hegemónico (Rabossi 2008). 
realidad había uno o dos temas buenos y los demás no los conocía ni magolla? Yo no hago eso. Todos los temas que pongo son hits". Presentar un servicio funcionaba hacia adentro como una credencial de prestigio y de conocimiento. Hacia fuera como una forma de inscribir la actividad en un trabajo digno. ${ }^{2}$

El dinero también hace ese recorrido múltiple. Feltran (2019) ha mostrado a partir del caso del robo de vehículos y la venta de drogas en Brasil el modo en que el dinero puede pasar de una esfera de lo ilegal a una legal: un auto es robado y luego vendido o intercambiado por droga. El vendedor se hace de dinero o vende droga - por la cual también consigue dinero - y luego lo gasta un shopping center transformando cualitativamente el dinero que pasa de ser sucio para limpio en cuestión de segundos. Este tipo de proceso "Não se trata de lavagem de dinheiro, mas de consumo. É o que se espera na economia global [...] justamente porque nessa escala impessoal, não há qualquer preocupação com a qualidade, mas sim com a quantidade de dinheiro" (Feltran 2019: 3). En el caso de la venta ambulante el proceso es circular. Ese dinero pasa de la esfera del trabajo a una que es cuestionada: la de la venta ambulante. Pero a su vez, los vendedores con ese dinero compran mercadería que nuevamente vuelve al "mundo formal".

Sin embargo, en esa circulación, en ese camino, el dinero adquiere diferentes valoraciones. Para Wilkis $(2018,2013)$ el dinero en el mundo popular suele estar bajo sospecha. Ese cuestionamiento no remite a las cosas en sí sino al circuito por el que circulan: algo que podríamos denominar el "mundo popular". No quiero decir con esto que sea un universo separado ("el mundo popular" y el "otro mundo formal"). Antes bien, es una configuración social - en tanto que es una red de interdependencias - espacializada. Las cosas (y las personas) no cambian solo de estatus por pasar de un actor a otro sino también por el lugar en el que se ofrecen y por cómo se lo hace.

Durante mi trabajo de campo presencié miles de rituales de venta. En ellos, ni vendedores ni futuros compradores solían cuestionar la legalidad de los productos aunque sí su calidad, tampoco se cuestionaba el "origen del dinero". Los vendedores se esforzaban por demostrar las cualidades y el cuidado de lo que ofrecían. Los que vendían alimentos enfatizaban en la marca y en la fecha de vencimiento. Los que vendían indumentaria en su calidad en la confección. Los que vendían CD grabados utilizaban altoparlantes para mostrar que funcionaban. También la confianza jugaba un lugar central. "Cualquier cosa lo podés cambiar, yo estoy acá todos los días. No hay problema”.

2 En los últimos años esta idea de que proveen un servicio se ha transformado en una reivindicación central de algunos grupos de vendedores para que sean reconocidos como trabajadores esenciales. Existe un trabajo político y una construcción de sentidos "hacia fuera" que los vendedores realizan a partir de la noción de servicio como sentido legitimante. Ver Fernández Álvarez (2018, 2019). 
Que no aparezca durante los rituales, sin embargo, no quiere decir que la "ilegalidad" no sea constitutiva del circuito. Cuando los productos ingresan en ese circuito adquieren ciertas particularidades. Los actores necesitan justificar la venta. Ellos mismos requieren justificar su lugar como trabajadores. Los propios actores saben que existe una construcción en torno a la legalidad de la actividad. Y ella puede ser activada circunstancialmente por otros actores. ${ }^{3}$

La mayoría de los vendedores no estaban registrados en la seguridad social por lo que no contaban con aportes, jubilación, obra social y tampoco pagaban impuestos. Esto ha posibilitado que otros actores activaran el discurso de la ilegalidad. En el caso de los que ofrecen productos en la vía pública, los comerciantes de locales se han quejado de una competencia desleal. También ha sido cuestionado el uso del espacio público para la venta de productos. Los que venden en los trenes están sujeto a otras relaciones y a otros discursos (y a otras disputas) aun cuando los productos ofrecidos puedan ser los mismos. No son las cosas ni las personas en sí las que dan cuenta de la legalidad/ilegalidad de la venta ambulante sino las relaciones que se establecen y el modo que se constituyen las actividades en tanto problema público.

En la venta ambulante las personas se tornan - al igual que las cosas - objeto de sospecha. ${ }^{4}$ Sin embargo, al igual que en el caso analizado por Feltran no son las cosas en sí, sino los sentidos y las relaciones las que legalizan/ilegalizan las cosas en función de los usos del derecho y la posibilidad de movilizar sentidos en diferentes esferas (Schijman 2019; Pires 2020). Los propios trabajadores dan cuenta de los usos de la ilegalidad y de su condición para demandar. En 2011, durante uno de los primeros meses de mi trabajo de campo se produjo una protesta que terminó con 14 detenciones y varios heridos. Un grupo de vendedores ambulantes cortaron las vías de la línea del ferrocarril en la que trabajaban. "Somos trabajadores tercerizados", decían. "Queremos pasar a planta permanente", manifestaban. En una entrevista a un canal de noticias uno de los vendedores decía: "Pedimos un puesto de trabajo en el ferrocarril. Queremos trabajar dignamente, sin represión. Queremos que una persona responsable se acerque a nosotros y nos brinde una solución inmediata."

La protesta se presentaba por el "temor a no poder trabajar". Durante mi trabajo de campo - al menos hasta 2015 cuando cambió la coalición de gobierno - no presencié grandes problemas para el trabajo. En las entrevistas los vendedores recordaban momentos de persecución y de dificultad para poder trabajar y los contraponían al momento actual que describían como de cierta tranquilidad. "Trabajador", "tercerizado", "planta permanente"

3 Por ejemplo, la Cámara Argentina de Comercio (CAC) y la Cámara Argentina de Mediana Empresa (CAME) realizan regularmente informes sobre la "venta ilegal".

4 Para algunos actores, la ilegalidad de la economía de los sectores populares suele estar marcada por una serie de (pre)supuestos: los pobres evaden impuestos, usan cosas truchas, roban (Fernández Álvarez et al. 2019). 
formaban parte de una gramática específica tendiente a construir la legitimidad de su práctica en oposición a un discurso que los declaraba ilegales y que los ponía de fuera de la ley. Los argumentos que se esgrimían públicamente deben entenderse en el contexto en el que se produjeron. Los vendedores intentaban subvertir ese discurso marcando que eran víctimas de la precarización y que no deseaban trabajar en negro. Al mismo tiempo, la posibilidad de inscribirse como "tercerizados" y de pedir su "pase a planta" - esto es ser trabajadores estatales con seguridad laboral - recuperaba un discurso público y un proceso que se venía desarrollando. Habían existido otros conflictos laborales en el ferrocarril. Según el vocero de la Unidad de Gestión Operativa Ferroviaria de Emergencia (UGOFE), "en los últimos dos meses la empresa incorporó a 2400 personas". El vocero de los empleados tercerizados, había dicho que en la línea Roca "1580 personas fueron incorporadas a planta permanente", pero que el corte "no tiene nada que ver con nosotros". 5

La circulación de personas y productos por la venta ambulante, entonces, produce una serie de prácticas que pueden negociarse y que juegan con la norma. El paso por el circuito genera cambios en las personas y en las cosas. Entender este espacio como homogéneo no permite ver que durante la circulación se van dirimiendo formas de construir lo legal y lo ilegal.

\section{La estética}

Una tarde en 2015 recibí un llamado de Rodrigo que estaba haciendo una consultoría. Me comentó que trabajaba para algunas empresas de productos masivos y que quería hacerme algunas preguntas en relación a la venta ambulante. Pese a mis dudas accedí a juntarme. El consultor me contaba que algunas empresas tenían miedo de que en manos de los vendedores ambulantes los productos perdieran su lugar en el mercado. La venta ambulante podría - aun cuando la venta ambulante era una excelente forma de publicitar productos nuevos y vender mucho en poco tiempo - quitar "valor social" a los productos.

Para Rodrigo los productos al pasar a la venta ambulante podrían cambiar de estatus. Eso no se debía a las cosas en sí, sino a su circulación por la venta ambulante. Así como Rodrigo, decenas de veces escuché dudas sobre la calidad de los productos por cómo eran presentados, por cómo estaban cuidados, por su terminación. La legalidad y la ilegalidad parecen tener estéticas particulares. ${ }^{6}$ El circuito de la venta está marcado por su condición visual-moral. Tomo la idea de estética de forma amplia para centrarme en la forma de los objetos.

5 https://tn.com.ar/sociedad/avellaneda-la-federal-desalojo-el-corte-en-las-vias-del-roca_51 107/ (última consultación en enero 2022).

6 Debo esta idea los comentarios de Brígida Renoldi. Sobre la importancia de la "forma" (Renoldi 2017) y la relación entre forma, objeto y cosa ver también Strathern (1999) y Miller (2005). En relación a los objetos como articuladores ver Latour (2008). 
La manera en que son dispuestos los productos, la forma en que son presentados, las propias características de lo que se ofrece imprimen una forma particular al circuito de comercio. Pienso aquí a lo estético no sólo como una condición artística ni como un atributo de belleza sino como una forma de construcción de lo social en las que se puede apreciar fronteras entre grupos. ${ }^{7}$ Lo estético debe entenderse en función de valores morales y de una lucha por imponer formas y proyectos de vida. No estoy aquí planteando la idea de que existe un gusto estético que se reproduce como forma de "lo popular". Aun cuando lo estético como argumento moral es parte de la producción de la violencia y del poder simbólico, ${ }^{8}$ los productos y las personas atraviesan las diferentes esferas. También adquieren múltiples formas y significado. Así - tal era la preocupación de Rodrigo - la diferencia de clase puede estar dada por lo que se consume, pero también por cómo se lo hace. Son las cosas, sus colores, su forma, la manera en que son presentadas y lo que ello dice en situaciones particulares. Los productos y las personas pueden tener diferentes materialidades que revelan diferentes sistemas de valor dentro de un mismo campo de prácticas (Meyer 2005). En la estética se generan luchas políticas por imponer formas de vivir en las que diferentes actores agencian sobre ello. No son sólo los productos en sí los que son estéticamente diferentes sino el circuito. Lo estético debe comprenderse en su dimensión territorial.

No todas las personas cuestionan la forma en que son presentados los productos. Sin embargo tanto en mis observaciones como en las entrevistas, la forma en que eran mostrados, cuidados o empaquetados solía ser cuestionado por algunas personas, en general las que se consideraban de clase media. "Mirá como está puesto eso. No puede estar muy cuidado. Andá a saber dónde estuvo, dónde lo guarda", me dijo una tarde una pasajera en relación a las galletas que vendía José. "A mi me genera duda. Qué sé yo. Me da asco", me dijo Esteban, un joven que se consideraba de clase media en relación a manera en que presentaba y vendía los alfajores Ignacio. "Vos si vas a un quiosco o a un bar sabes. Las cosas están ahí puestas, ordenadas iAcá qué se yo!”, terminó

7 Para Rancière: "El término estética designa: no la teoría del arte [...] sino un régimen específico de identificación y de pasamiento de las artes: un modo de articulación entre maneras de hacer, formas de visibilidad de esas maneras de hacer y modos de pensabilidad de las relaciones, que implican una cierta idea de la efectividad del pensamiento." (Rancière 2009: 7) A su vez, retomo los presupuestos de Gell (1998) sobre la antropología del arte. Dice: "la antropología del arte no puede ser el estudio de los principios estéticos de tal o cual cultura, sino de la movilización de tales principios o lo que se les parezca, en el curso de la interacción social" (Gell 1998: 34). No es este mi interés, ni es hacer una "teoría específicamente antropológica del arte" ni estudiar objetos artísticos. Pero si marcar que la "estética" se produce en la interacción y que depende de las relaciones y sobre todo que los procesos de construcción material y simbólico de los objetos se interrelacionan y que generan formas de relación específicas entre agentes humanos y no humanos. Ver también Miller (2005).

8 Sobre violencia simbólica y poder simbólico como constructor de realidad y de producción de jerarquías ver Bourdieu (1977). 
diciendo. "¿Viste esas medias que vende el chico ese? Yo no sé cómo las consiguió, dónde las guardó. Las saca de un bolso roñoso. No las quiero ni tocar." - me dijo Estela, una secretaria de 45 años que usa el tren para ir a su trabajo.

Tanto las personas, las cosas y el lugar donde se ofrecen eran cuestionados. Todo espacio se construye en relación a otro (Gordillo 2004). La espacialización de los productos genera una evaluación estética relacional: los productos que se ofrecen en el tren pueden ser los mismos que los que se ofrecen en el "mercado formal". Sin embargo, en el circuito ambulante adquieren otras características que los deslegitiman y los vuelven desconfiables. Se produce un fetichismo de la estética o una fetichización del cuidado que genera divisiones entre productos "buenos" y "malos" a partir de la valoración estética de los productos y de las personas. Durante el trabajo de campo, varias personas referían a cierta homologación entre producto y persona, lo que producía una (des)valorización mutua.

De hecho, mover un producto de una estética a otra es uno de los componentes centrales de la venta de indumentaria en Buenos Aires. Varios dueños de locales de ropa compran sus mercaderías en locales alejados del centro de la ciudad donde están presentados de forma amontonada. Los llevan a su local en los barrios céntricos donde los cuelgan en perchas, les dan espacio, los iluminan y duplican el precio. El caso de la venta ambulante - como las medias que venden José y Esteban - quedan en el mundo de lo informal. No hacen el camino de la formalización estética.

Si bien el producto puede ser el mismo, al entrar en un circuito con una forma diferente a la de los supermercados y quioscos que los sectores medios compran, la forma del producto cambia. Al entrar en la venta ambulante, un producto puede ser sospechado por su origen, por su cuidado, por su calidad. Ello se ve reforzado por el precio en el que se ofrecen. El valor del precio funciona - para muchas personas - como una forma de desconfianza. Si el precio del producto ofrecido es muy bajo "por algo es". Ese algo suele estar ligado a la "ilegalidad", "informalidad".

La capacidad de hacer uso del espacio público también remite a una estética particular. Varios autores que han marcado que el anonimato (la capacidad de pasar desapercibido) es un componente central de la vida urbana moderna (Perelman 2019). Esa capacidad es potestad de ciertos grupos sociales. Segato (2007) plantea que las personas llevan su territorio a cuestas, en el cuerpo. Los vendedores "traen" su cuerpo mientras venden. Esos cuerpos tienen marcas, tienen adherencias (Ahmed 2004) que dan cuenta de un reparto desigual de los sensible (Rancière 2009). ${ }^{9}$ La estética de las personas y de los productos es

9 Los sectores populares no suelen entrar en la concepción hegemónica del cuerpo. Parte del racismo blanco en Argentina remite a la construcción de los sectores populares a partir de su corporalidad y de su "color" (Perelman 2021). 
parte del posicionamiento que hacen grandes sectores de la población de los vendedores como informales e ilegales.

Así como los productos pueden inscribirse en diferentes circuitos y esferas la circulación de personas es otra dimensión central de estos circuitos. Si ciertos grupos sociales pueden aparecer como fuera de lugar en ciertos contextos, es la capacidad de negociar y de inscribir su tarea en el ámbito del trabajo lo que les puede permitir acceder a los espacios de trabajo. Son las figuras que se pueden movilizar en el espacio público en función de lo que las personas consideran legítimo. Ello posibilita que una actividad pueda ser ilegalizada o legitimada. Inscribirse como vendedores es intentar movilizar figuras legítimas en el espacio público. Pero son también la corporalidad, la forma de vestirse, la manera de estar en el espacio público rasgos centrales de la venta ambulante, de su estética. Por un lado, no pueden pasar desapercibidos porque requieren ser reconocidos para poder vender. Por otro lado, ese "territorio a cuestas" funciona en ciertos ámbitos (algunos tramos del ferrocarril y en los ómnibus) como una marca distintiva, una marca estética de clase. La espacialidad de la práctica es central para comprender la cualidad estética. Este reconocimiento se produce en un doble juego: el paso de personas morales a individuos identificables. Ello contribuye a la generación de lazos interpersonales que son un componente central de la venta.

Estaciones de tren, trenes, colectivos, calles, adyacencias de espacios muy circulados configuran esos espacios. Es posible reconocer una evaluación moral desde "afuera" de estos lugares. Sectores medios - y muchos investigadores evalúan estos espacios a partir de "otra estética". La forma de ser presentados, cuidados, mostrados, vendidos, empaquetados difiere de los centros comerciales que se plantean como la forma "normal" - o neutra. Que los productos entren en este circuito genera nuevas articulaciones y formas específicas de comprender los productos y las personas que allí viven. Tal era la preocupación de Rodrigo.

Lo estético marca no sólo los productos sino también la circulación de billetes. En su etnografía de las prácticas comerciales de un negocio mayorista de Buenos Aires, Pires (2013) muestra el modo en que el intercambio de billetes articula y da cuenta de diferentes valores materiales, morales, éticos y estéticos. Pires da cuenta de cómo los billetes por más de tener la misma denominación tienen diferente valor. A los que son menos apreciados o con los que existe una distancia social más grande, los comerciantes suelen darles los billetes más rotos, que suelen asociarse con la venta ambulante. Recibir entonces un papel en mejor o peor estado refiere al estatus social que uno tiene en esa configuración. Lo estético también tiene un valor interno que se pone en juego y que se comprende a partir de las relaciones que se generan dentro de la venta ambulante.

Los precios, lo que se vende, cómo se vende, como se presenta forman parte de arreglos entre vendedores. Es por ello que el precio, la estética, el producto 
mismo son componentes centrales del circuito, antes que una característica intrínseca de un lo popular, lo ilegal o lo informal.

La estética de lo informal es central para comprender las posibles inscripciones de una actividad, una práctica o un producto dentro del ámbito de lo legal-ilegal como ocurre con las construcciones en sectores populares y en los barrios de clases medias y bajas. Bourdieu y Passeron (1977: 44) plantean que "todo poder de violencia simbólica, o sea, todo poder que logra imponer significaciones e imponerlas como legitimas disimulando las relaciones de fuerza en que se funda su propia fuerza, añade su fuerza propia, es decir, propiamente simbólica, a esas relaciones de fuerza". Es parte del funcionamiento de la hegemonía. Son las relaciones sociales y las capacidades de los actores las que posibilitan inscribir ciertas maneras de estar, de presentar, de usar las cosas que permiten ese juego de poder (Telles 2009). Lo estético - que es un espacio de disputa - puede inscribir productos en la trama de la informalización e ilegalización social.

\section{A MODO DE CIERRE}

Schijman (2019) sostiene que la noción de economía informal es una formulación demasiado general para aprehender formas de legitimidad y de derecho en la búsqueda de estabilidad social. Las prácticas de solidaridad y de derecho en esa búsqueda de estabilidad (y en el cambio de una esfera y de la otra) son centrales. Plantea que el derecho no emana solamente del Estado sino también de las "costumbres", los usos precedentes y una producción de comunidad. Las prácticas sociales no son simplemente reflejos de las normas jurídicas preexistentes. ${ }^{10}$ No existen dos legalidades o dos mundos dicotómicos (legal/ ilegal; formal/informal) sino formas colectivas de hacer (con) la ley (en las que también juegan su rol las políticas públicas y los agentes estatales). La ley se vuelve flexible.

Pensar esos circuitos donde tanto el derecho como la economía son utilizados como parte de prácticas flexibles posibilita adentrarnos en configuraciones específicas en las que se negocian límites y sentidos.

En la venta ambulante circulan productos y personas, discursos, moralidades. Ese circular es plural y múltiple. Centrarse en esa circulación y en el modo en que las personas de carne y hueso activan formas legítimas de estar, vender, presentarse, mostrarse, usar la ley prácticamente permite comprender la producción de formas desiguales de entender las prácticas sociales. La capacidad de movilizar sentidos de justicia va más allá y no sólo se centra en el Estado, sino en las diferentes capacidades que tienen los actores para movilizar 
situacionalmente los discursos. En esa interpretación es que se ponen en juego los discursos en torno a lo legal/ilegal, entre lo legítimo/ilegítimo. Que los agentes puedan o no imponer formas depende no solo de la capacidad que tienen los actores de leer las situaciones sino también del entramado de relaciones de poder. La estética, por ejemplo, es un espacio de disputa que permite comprender esa pugna por imponer formas de vivir.

Seguir las cosas y las pugnas por la estética permite comprender que los mercados se producen a partir de usos locales del derecho y de la economía que deben entenderse situacionalmente. Las mercaderías, los precios, las formas de colocar los productos, de presentarlas, las personas son parte de esa configuración que se produce de manera constante tanto a partir de las interacciones entre los actores como de los usos y de la imputación moral que otros actores hacen de ella. Esta postura invita a no pensar de forma apriorística los límites de los circuitos a partir de indagar en los procesos concretos (y no en los discursos abstractos).

\section{BIBLIOGRAFÍA}

AGUIAR, José Carlos G., 2013, "Smugglers, fayuqueros, piratas: transitory commodities and illegality in the trade of pirated CDs in Mexico", PoLAR: Political and Legal Anthropology Review, 36 (2): 249-65.

AHMED, Sara, 2004, The Cultural Politics of Emotion. Edimburgo: Edinburgh University Press. ALBA VEGA, Carlos, Gustavo LINS RIBEIRO, y Gordon MATHEWS (eds.), 2015, La Globalizacion desde Abajo: La Otra Economía Mundial. México, DF: El Colegio de México.

BOURDIEU, Pierre, 1977, "Sur le pouvoir symbolique", Annales: Histoire, Sciences Sociales, 32 (3): 405-411.

BOURDIEU, Pierre, y Jean-Claude PASSERON, 1977, La Reproducción: Elementos para Una Teoría del Sistema de Enseñanza. Barcelona: Laila.

FELTRAN, Gabriel, 2019, "(Il)Licit economies in Brazil: an ethnographic perspective”, Journal of Illicit Economies and Development, 1 (2): 1-10.

FERNÁNDEZ ÁLVAREZ, Maria Inés, 2018, "Más allá de la precariedad: prácticas colectivas y subjetividades políticas desde la economía popular Argentina." Íconos - Revista de Ciencias Sociales, 62: 21-38.

FERNÁNDEZ ÁLVAREZ, María Inés, 2019, "Relaciones de parentesco, corporalidad y afectos en la producción de lo común: reflexiones a partir de una etnografía con trabajadores de la economía popular en Argentina", Revista de Estudios Sociales, 70: 25-36.

FERNÁNDEZ ÁlVAREZ, María Inés, Sandra WOLANSKI, Dolores SEÑORANS, Florencia PACífICO, Carmina PEDERIVA, María Paz LAURENS, Silvana SCIORTINO, Santiago SORROCHE, María Victoria TARUSELl, y Cecilia CAVIGLIASSO, 2019, Bajo Sospecha: 
Debates Urgentes sobre las Clases Trabajadoras en la Argentina. Buenos Aires: Callao Cooperativa Cultural.

GELL, Alfred, 1998, Art and Agency: An Anthropological Theory. Oxford y Nueva York: Clarendon Press.

GORDILlO, Gastón, 2004, Landscapes of Devils: Tensions of Place and Memory in the Argentinean Chaco. Durham: Duke University Press.

GUIMARÃES, Nadya Araujo, 2019, "Os circuitos do cuidado: reflexões a partir do caso brasileiro”, Séminaire Publique de l'Equipe CRESPPA-GTM, 1-38. Paris.

KESSLER, Gabriel, 2013, "Ilegalismos en tres tiempos", in Robert Castel, Gabriel Kessler, Denis Merklen y Numa Murard, Individuación, Precariedad, Inseguridad iDesinstitucionalización del Presente? Buenos Aires, Barcelona y México, DF: Paidós, 109-166.

LATOUR, Bruno, 2008, Reensamblar lo Social: Una Introducción a la Teoría del Actor-Red. Buenos Aires: Manantial.

LINS RIBEIRO, Gustavo, 2018, Otras Globalizaciones. México, DF: Gedisa - Universidad Autónoma Metropolitana.

MEYER, Fred, 2005, "Some properties of art and culture: ontologies of the image and economies of exchange”, in Daniel Miller (ed.), Materiality. Durham: Duke University Press, 88-1 17.

MILLER, Daniel (ed.), 2005, Materiality. Durham: Duke University Press.

MISSE, Michel, 2008, "Dizer a violência”, Katálysis, 11 (2): 165-66.

PERELMAN, Mariano, 2013, “Trabajar en los trenes: la venta ambulante en la ciudad de Buenos Aires”, Horizontes Antropológicos, 19 (39): 179-204.

PERELMAN, Mariano, 2018, "Disputas en torno al uso del espacio público en Buenos Aires”, Caderno CRH, 31: 87-98.

PERELMAN, Mariano, 2019, "La marche dans la production de l'inégalité sociale: la collecte informelle des déchets à Buenos Aires”, Espaces et sociétés, 4 (179): 145-160.

PERELMAN, Mariano, 2021, "Dollars, pesos, and planes: reconstruction of class borders in the second government of Cristina Fernández de Kirchner (2011-2015)”, Dialectical Anthropology, 45 (3): 275-296.

PINHEIRO-MACHADO, Rosana, 2018, Counterfeit Itineraries in the Global South: The Human Consequences of Piracy in China and Brazil. Nueva York: Routledge.

PIRES, Lenin, 2013, "Entre notas e moedas: trocas e circulação de valores entre negociantes em Constitución”, Horizontes Antropológicos, 19 (39): 149-78.

PIRES, Lenin, 2020, "Mercados informales y la circulación de la tolerancia: mercancías políticas y relaciones entre sociedad y Estado", Cuadernos de Antropología Social, 51: 135-152.

PITA, María Victoria, 2005, "Mundos morales divergentes: los sentidos de la categoría familiar en las demandas de justicia ante casos de violencia policial”, in Sofía Tiscornia y María Victoria Pita (eds.), Derechos Humanos, Tribunales y Policías en Argentina y Brasil: Estudios de Antropología Jurídica. Buenos Aires: Antropofagia, 83-1 18.

RABOSSI, Fernando, 2008, "En la ruta de las confecciones", Crítica en Desarrollo, 2: 151-17 1. RANCIÈRE, Jacques, 2009, El Reparto de lo Sensible: Estética y Política. Santiago: LOM.

RENOLDI, Brígida, 2015, "Estados posibles: travesías, ilegalismos y controles en la triple frontera”, Etnográfica, 19 (3): 417-440.

RENOLDI, Brígida, 2017, "Las continuidades de lo discontinuo: el trabajo policial y judicial en casos de narcotráfico en la frontera de Argentina y Paraguay", in Brígida Renoldi, Santiago Álvarez y Salvador Maldonado Aranda (eds.), Estado, Violencia y Mercado: Conexiones Etnográficas en América Latina. Buenos Aires: Editorial Antropofagia, 159-184. 
SANDOVAL HERNÁNDEZ, Efrén, 2017, "La economía de la fayuca y la transitividad legal-ilegal, informal-criminal", in Brígida Renoldi, Santiago Álvarez y Salvador Maldonado Aranda (eds.), Estado, Violencia y Mercado: Conexiones Etnográficas en América Latina. Buenos Aires: Editorial Antropofagia, 219-233.

SCHIJMAN, Emilia, 2019, A qui appartient le droit? Ethnographier une économie de pauvreté. Paris: Maison des Sciences de l'Homme, LGDJ.

SEGATO, Rita Laura, 2007, La Nación y Sus Otros: Raza, Etnicidad y Diversidad Religiosa en Tiempos de Políticas de la Identidad. Buenos Aires: Prometeo.

SIGAUD, Lygia, 1996, "Direito e coerção moral no mundo dos engenhos", Estudos Históricos, 9 (18): 361-388.

STRATHERn, Marilyn, 1999, Property, Substance and Effect: Anthropological Essays on Persons and Things. Londres: Athlone Press.

TELlES, Vera da Silva, 2009, "Nas dobras do legal e do ilegal: ilegalismos e jogos de poder nas tramas da cidade", Dilemas - Revista de Estudos de Conflito e Controle Social, 2 (5-6): 97-126.

THEVENOT, Laurent, 2015, “Teoría y práctica de las clasificaciones socioprofesionales", Papeles de Trabajo, 9 (15): 44-79.

THEVEnOt, Laurent, 2016, La Acción en Plural: Una Introducción a la Sociología Pragmática. Buenos Aires: Siglo Veintiuno Editores.

TISCORNIA, Sofía, 2007, "Lo trucho", Debates en la Cultura Argentina, 2005-2006, tomo 4, 1. Buenos Aires: Emec, 96-104.

WILKIS, Ariel, 2013, Las Sospechas del Dinero: Moral y Economía en la Vida Popular. Buenos Aires: Paidós.

WILKIS, Ariel, 2018, The Moral Power of Money: Morality and Economy in the Life of the Poor. Stanford: Stanford University Press.

ZELIZER, Viviana, 2004, "Circuits of commerce", in Jeffrey C. Alexander, Gary T. Marx y Christine L. Williams (eds.), Self, Social Structure, and Beliefs: Explorations in Sociology. Berkeley: University of California Press, 122-44. 